\title{
The Globalisation of Firms as Social Systems
}

\author{
Thomas Borghoff \\ Victoria University of Wellington, Wellington, New Zealand
}

\begin{abstract}
Existing theories of the globalisation of firms fall short of integrating evolutionary, self-reproductive mechanisms. This conceptual paper serves to provide an overview on existing literature in systems theory and to develop a basic framework for the study of evolutionary processes in the globalisation of firms. Ontological, epistemological, and methodological consequences of an evolutionary social systems approach to globalisation will be discussed.
\end{abstract}

Keywords: globalisation, evolutionary theories, system theories, SMEs

\section{Introduction}

Theories explaining the internationalisation or globalisation of firms overwhelmingly define firms as goal-directed organisations. The focus is on intended development processes based on decision-making. Learning-based theories such as the incremental models of the Uppsala School (Johanson \& Vahlne, 1977) and the Helsinki School (Luostarinen, 1980) also include learning processes but do not explicitly explain the underlying evolutionary mechanisms that drive the globalisation of firms. A firm that is conceptually constituted by individuals as its elements cannot reproduce itself as individuals do not reproduce themselves in the organisation — only their communications and actions do. In order to allow for a study of authentic evolutionary mechanisms based on self-reproduction, an ontological change in the question of what a firm is would be necessary. In this paper, social systems theory will be used to develop a model of a firm that is constituted by communication and actions rather than by individuals and assets. On this basis, the observation of self-reproduction (i.e., on the basis of the own elements) becomes possible. The observation of globalisation processes thus gets a totally different angle as the self-reproduction of a firm is embedded in a co-evolutionary interplay with its globally differentiated environment.

\section{Properties of Firms as Social Systems}

An evolutionary perspective on the globalisation of firms has to be embedded within a conceptual framework that allows for the application of evolutionary principles to the firm level. In order to have evolutionary properties, a firm has to be autonomous in its reproduction. This means that it has to be self-reproducing. The traditional instrumental perspective of organisations does not allow for such an approach because individuals as the elements of an organisation do not reproduce themselves in the organisation. Neither, they are exclusively elements of only one organisation. Hence, an application of strict evolutionary principles

Thomas Borghoff, Ph.D., School of Marketing and International Business, Victoria University of Wellington.

Correspondence concerning this article should be addressed to Thomas Borghoff, PO Box 600, Wellington. E-mail: thomas.borghoff@vuw.ac.nz. 
within the instrumental perspective is not possible. However, the application of evolutionary principles to organisations is possible when the latter are conceived as autopoietic systems as will be argued in the following. In a first step, basics in systems theory will provide a basis for the conceptualisation of firms as autopoietic social systems.

\section{Theoretical Basis of a Social Systems Perspective}

Systems theories provide a general framework for the observation of social evolutionary processes. General systems theory provides basic properties and mechanisms characterising natural systems, e.g., the basic design of production and regulation processes or the inherent tendency for growth. Theories of living systems already describe the transition of systems toward states of higher order and differentiation. Such organic forms are considered as the expression of processes of an ordered system of forces, constituting a process of dynamic morphing (von Bertalanffy, 1950, pp. 26-27). A living system is characterised by autopoietic reproduction. The theory of autopoiesis developed in cognitive biology marks the watershed in the integration of autopoietic principles in social systems theory because cognitive and emotional processes are the basis for social processes. The three levels of systems theory are outlined briefly in the following.

Firms as open systems: General systems theory. General systems theory is a kind of meta-theory that serves to integrate various theories from natural to social sciences. The roots were developed in the Natural Sciences by von Bertalanffy (1950), von Hayek (1945), and other chemists, physics, and biologists. General systems theory was enhanced by contributions from social sciences and established a common language and concepts to describe and observe different kinds of systems. While the general systems theory provides some common bases for all kinds of systems, several streams of this theoretical approach were adapted to more specific research areas.

Systems can be differentiated into closed and open systems. Closed systems, like machines, have no elements of self-organisation and exchange with their environment. In contrast, open systems like organisations are in a continuous exchange with their environment (Katz \& Kahn, 1978, pp. 125-126). Katz and Kahn further define nine properties of open systems: (1) importation of energy; (2) through-put; (3) output; (4) cycles of events; (5) negative entropy; (6) information input and negative feedback; (7) steady state and dynamic homeostasis; (8) differentiation; (9) equifinality (Ibid., pp. 20-25).

In contrast to physics (2nd law of thermodynamics), biological and social evolution is accompanied by progressive structuration such as that introduced by the division of labour in the history of human societies (Prigogine, 1976, p. 94). The basic principle of the biological and social universe is increase of diversification, heterogeneity, and symbiotisation. What survives is not the strongest, but the most symbiotic (Maruyama, 1976, p. 202).

"Self-regulating, equilibrium-based, and thus deviation-counteracting systems" were the object in the first phase of cybernetic thinking, termed Cybernetics I by Mayurama (1963). Cybernetics II, on the other hand, focuses on circular processes, which constitute autonomous, self-referential units with the capacity for self-structuration and self-organisation (Schulz, 1993, p. 44). The difference between Cybernetics I and II is that the deviation-counteracting system has mutual negative feedback between the elements in it, while the deviation-amplifying system has mutual positive feedback between the elements in it (Mayurama, 1963, p. 166). 
Inherent in this perspective is the principle of learning, i.e., the increase in the adaptability and self-complexity of the system. Cybernetics II is focused on change, instability, and self-reinforcing processes as well as evolution and co-evolution (Schulz, 1993, p. 26).

The properties of firms as open, evolving systems provide important hints to general behavioural traits of firms. For example, firms are characterised by an inherent drive towards growth and increasing complexity. This explains the traditional trend towards large, diversified firms. The growth principle exerts a strong influence on the evolution of a firm if not addressed consciously by decision-makers, e.g., in order to stress profitability or flexibility rather than size. At a macro-level, globalisation itself is a result of this inherent drive of social systems towards growth and increasing extension.

General systems theory also provides the basic building blocks in the constitution of systems. There is a basic production or transformation process, which provides the necessary resources in co-evolution with the environment. The internal organisation is based on equifinal and adaptable structures and regulatory processes based on information. Globally operating firms develop a maximum complexity with dispersed and differentiated subsystems, each characterised by its own production and regulatory processes and embedded in a co-evolution with both the integrating internal organisational context and the external local context. A globally operating firm thus is subject to fluctuations at multiple levels and depending on a resource exchange with multiple other systems in different local contexts. Globally operating firms are also exposed to different degrees of dynamics in different national or regional markets.

Theory of living systems. The next step from the general systems theory to social organisations is the theory of living systems. The theory of living systems is a general systems theory of the organisation (Duncan, 1972, p. 518). Living systems are open systems, maintaining themselves in exchange of materials with the environment, and in continuous building up and breaking down of their components. Such systems are never in true equilibrium, but in a steady state. In a steady state, an open system may attain a time-independent state where the system remains constant as a whole and in its phases, though there is a continuous flow of the component materials (von Bertalanffy, 1950, p. 23). Contrary to closed systems, which are subject to the second law of thermodynamics ("entropic death" of systems), in organic development and evolution, a transition toward states of higher order and differentiation seems to occur (Ibid., p. 26). Organic forms are considered as the expression of processes of an ordered system of forces, constituting a process of “dynamic morphing” (Ibid., p. 27).

In terms of living systems, firms develop idiosyncratic properties in structural terms. They develop an identity and an individual form of organisation, which manifests itself in changing structural arrangements. Behaviour and structure of a firm is recursively linked to other systems in its social environment. In the global context, the organisation, structure, consensual domains, and structural couplings are subject to cultural and contextual differences that call for the differentiation of internal structures and the development of integration mechanisms.

Theory of autopoietic systems. With the concept of autopoietic systems entered the element of evolution into systems theory. Autopoietic systems are capable of self-reference, self-organisation, and self-reproduction. Autopoiesis is a term of Greek derivation and means self(auto)-production (poiesis; poein) (von Krogh \& Roos, 1995, p. 33).

Contrary to autopoietic systems, in allopoietic systems, the organisation itself does not produce the elements 
and processes constituting it as a unity (Maturana, 1985, p. 177). Allopoiesis is defined as a production of something else than itself. In management theory, it resembles the traditional perspective of purposive, rational planning and implementation, including the construction of formal hierarchical organisation, in which lower levels are designed and controlled. Informal and emergent properties from this view are excluded or invisible. Allopoietic systems are undoubtedly the precursors of autopoiesis in social systems-allopoiesis is the framework, a condition, within which autopoiesis can take place (Zeleny, 1981, pp. 95-96). Autopoiesis and allopoiesis are complementary rather than exclusive characterisations for a system (Varela, 1981, p. 39).

A basic principle of social systems is that each social system is embedded in a wider social system in a recursive way while all are autopoietic. Social systems are hence characterised by the "principle of recursiveness" (Malik, 1984). A social system and its subsystems all have the same basic structural properties. Therefore, they are also characterised by the "principle of self-similarity" (Ibid., p. 104). All subsystems therefore are wholes with boundaries and all characteristics of a social system. For example, within an organisation, all organisational units have defining boundaries, a formal and an informal structure, an identity, thus leading to comparable, self-similar principles of organisation. Within such a layered or multi-level structure, allopoietic organisation has to define arenas for self-organisation (zu Knyphausen, 1988, p. 309). Adapted to firms this would mean that units at hierarchically lower levels are purposively structured and given orders by higher levels while maintaining their self-organisation within defined limits and residual spaces. Such a conscious context management proved to be particularly valuable in international management (Bartlett \& Ghoshal, 1987). The task of management is to stimulate the growth of a network of decision processes, systems, programmes, and rules, that is to say, an organisation, which may be considered effective in attaining institutional objectives. One basic objective is to develop the autonomous dynamic unity of the organisation (i.e., an autopoietic operation). The network of decision processes must produce components capable of recursively generating the same network through their interactions. In this sense, a manager is the catalyst rather than the designer of an organisation (Zeleny \& Pierre, 1976, p. 161).

Individuals are the nodes between several social systems (Maturana, 1985, p. 178). A cognitive or social system can create consensual linguistic fields and self-consciousness by orientational interaction with similar systems and with itself (Ibid., p. 71). The fact is that information does not exist independent of a context of organisation that generates a cognitive domain, from which an observer community can describe certain elements as informational and symbolic (Varela, 1981, p. 45). Globally operating firms thus have to cope with multiple diverse consensual domains at different geographical and business-oriented levels. As observers know and create their environment through interactions with it (Uribe, 1981, p. 51), such firms have to develop their consensual domains in an evolutionary interplay with their respective local and business environments while maintaining an overlapping consensual domain vis-à-vis their global environment as a whole.

The dual character of social systems. Despite the conceptual problems in the adaptation of the theory of autopoietic systems to social systems, Jantsch (1986, p. 161) contends that:

Genetic, epigenetic, social, and socio-cultural evolution appear to be connected by homologous, and not only analogous principles_-principles which in different variations and on different levels of evolution are of the same type as they all stem from the same origin.

In a similar vein, Malik (1993, p. 101) contends that genetic, epigenetic, social, and socio-cultural evolution 
are linked through homologous principles and expose an astonishing coherence in form of circular logics of trial-and-error processes.

A conception of social systems being constituted by individuals as elements allows for an allopoietic perspective. It may hence provide a teleological approach to the evolution of systems. This is an important contribution as intended influences on the reproduction of a social system from outside the system's boundaries always have allopoietic connotations. Due to the principle of recursiveness and self-similarity, this also applies to influences from other subsystems within the same system, e.g., the influence of headquarters on subsidiaries in multinational enterprises (MNEs). Both headquarters and subsidiaries are organisational units and as such constitute themselves a social system in the nested hierarchy of social systems.

In contrast to the allopoietic approach, which still assumes individuals to be the defining elements of social systems, the adaptation of the concept of autopoiesis to social evolution appears to be conceptually possible by an adaptation of the mechanism of the reproduction of components. Social acts as communication, legal acts etc., may be components of self-referential, but not of autopoietic systems: They do not exist independent from the existence of acting individuals and in physical-biological sense communicative acts do not produce new communicative acts themselves but trigger them in individuals. A social system may only be regarded as being autopoietic by an ontological change of the system level. This implies: (1) a complete exclusion of acting and communicating individuals from the concept of social system; and (2) a conceptualisation of social acts (communications, actions) as the only components of the social system. It is thus possible to develop an ontology of systems, in which the states adopted by the components of an allopoietic system become the components of an ontologically higher system, which may be regarded as a social system of a second level or order (Roth, 1986, p. 212). A primary social system in terms of a population, e.g., a society, or tribe-may be conceived as an autopoietic system constituted by individuals as their elements. On the one hand, organisations are primary social systems that are allopoietic as individuals do not reproduce themselves. On the other hand, functional social systems and organisations are also autopoietic systems of a second level, or secondary social systems, as they are constituted by social acts as their elements. The individuals constituting a social system by their social acts do not enter the system as elements. Rather, they may be conceived as nodes stakeholders and primary resources, which provide all necessary tangible and intangible resources by communication and action.

The elements of the autopoietic social system are all communications and actions on its behalf and from its perspective—not the constituting individuals.

Members of a social system constitute a primary, allopoietic social system, which serves as the basis for the formation of a secondary, autopoietic social system. The latter is constituted by social acts on its behalf and from its perspective, which may consequently also be provided by individuals that are not formal members of the primary system. As individuals are not exclusive elements of one social system, they can contribute to the autopoietic reproduction of various secondary social systems by providing them with actions and communications belonging to their path-dependent reproduction. On balance, social systems are both autopoietic in their underlying meaning-based reproduction and allopoietic, as they depend on the intentions of the individual stakeholders. Social systems emerge on the basis of consensual domains formed and implemented by the founding individuals. They grow as other individuals or social actors increasingly contribute to their reproduction internally, or externally as exchange partners. Globally operating firms are constituted by 
individuals and social actors from different cultures and have to develop an organisation of overlapping local and global consensual domains.

\section{Properties of Firms as Allopoietic Systems}

The view of organisations as allopoietic social systems is the traditional view of purposeful, instrumental, and goal-directed systems constituted by individuals. It has traditionally been dominating organisation and management theory. With the exception of ecological organisation theories and institutionalisation theory, the perspective is basically voluntaristic and functional. The focus has traditionally been on formal organisation. Elements of organisation are formal roles and organisational units. The function of the organisation is to attain the formulated purpose and specific goals by means of specialisation and co-ordination of organisational processes, roles, and units.

From the allopoietic perspective, teleological processes of planning and decision-making drive evolution. All properties of organisations, which may not be observed by this formal and instrumental perspective, basically become a residual in the shadow of this lens. For example, Tichy (1981, p. 225) noted that "the prescribed organisation structure provides the pegs upon which the emergent networks hang”, thus putting all organisational properties, which are not formally intended and prescribed into the informal drawer. This unknown organisational world may be contained or even integrated by context management, but remains a black box theoretically and in managerial practice. Emergent strategies may occur and shadow options may exist but are not part of the standard repertoire in management. Informal organisation hence often remains a residual task for the human resource management as most efforts to explain it have been made by concepts of motivation, incentives, and social cohesion. Organisational aspects themselves are basically out of sight from the allopoietic perspective, as, even by definition, it cannot explain organisation from within and by its own logic.

On the other hand, the allopoietic perspective provides directly applicable knowledge for those who have an instrumental stake in organisations. It provides insights about how goal attainment, instrumental and intentional behaviour as well as efficient organisational structures and processes may be designed and implemented. This literature comprises both organisation theory (e.g., contingency theory) and management literature, particularly on organisation structure and design.

While the designs of formal organisation structure and processes traditionally have been the main targets of organisation research, the focus is increasingly on dynamic meaning-related organisation as reflected by the knowledge-based view. Routines, capabilities, best practices, and core competencies have become main concepts in theoretical and instrumental organisation literature. Particularly in the global context such a reorientation may be very inspiring as it directs more attention to underlying differences and basic layers in the organisation of dispersed organisational units. For example, Egelhoff (1993, pp. 204-205) contends that a key function of formal MNE structure is that managers across the company know where specific sources of knowledge and capability are. As long as the locations tend to be fairly stable, managers are generally familiar with how to access them. With increasing dynamics in transnational structures, formal structure begins to lose its value as an accurate and stable directory of where knowledge and capability reside and how they can be accessed. A shift in the focus from formal regulations to a dynamic knowledge perspective thus provides more flexibility also for the instrumental, allopoietic perspective of organisation in the global context. 


\section{Properties of Firms as Autopoietic Systems}

Autopoietic systems are capable to reproduce themselves. In this view, firms are not only instruments to achieve the goals of the stakeholders but they "take a life on their own" (Selznick, 1947). An evolutionary perspective of social systems can only be based on an autopoietic view as it allows conceiving firms as autonomous systems reproducing themselves. Of course, a conceptualisation of firms as autopoietic social systems presupposes a definition of respective properties. The most important difference between allopoietic and autopoietic social system level is that the latter is constituted by meaning and social acts rather than by individuals as their elements.

Meaning as the basis of social systems. While psychic systems (individuals) are constituted on the basis of a unified (self-referential) nexus of conscious states, social systems are constituted on the basis of a unified (self-referential) nexus of communications. The co-evolution of both has led to the common evolutionary achievement of meaning, employed by psychic as well as social systems. Both kinds of systems are ordered according to it, and for both it is binding as the "indispensable, undeniable form of their complexity and self-reference” (Luhmann, 1995, p. 59). Meaning extracts differences to enable a difference-based processing of information (Ibid., p. 63). The processing of meaning follows the principles of distinction and indication (Spencer-Brown, 1972, p. 3). The mechanism for the construction and description of a form (an object) is therefore-Draw a distinction! (Ibid.). While doing this in a two-dimensional plane is quite simple (a line drawn between two objects may be sufficient), social systems expose a high degree of complexity so that the introduction of central guiding differences is critical to co-ordination of decision-makers and of globally dispersed activities. Globally operating firms have to identify the most important guiding differences in their heterogeneous context in order to augment their evolutionary capability. Intercultural comparisons may be difficult because cultures diverge in the semantics of the very first proceeding of this compulsion to self-change (Luhmann, 1995, p. 64). This causes serious implications for globally operating firms. The meaning-based structure of social systems does not only differ with regard to content but also in the process of selective reproduction. Selection mechanisms and criteria may be different between cultural contexts and respective social systems.

Differences in meaning structures do not only exist between cultures. Meaning is always system-specific. Only shared meaning allows for interaction and communication between systems. Meaning may be incorporated in worldviews, values, norms, roles, and organisational cultures. It is produced and negotiated in ongoing interactions (Willke, 1994b, p. 175). Meanings are open, have no ultimate origin or ultimate truth. Meanings are bounded by socio-cultural limits (Dachler \& Hosking, 1995, p. 9). For example, efficient management structures and practices differ in many important respects because business environments do so as well (Whitley, 1992, p. 122). The socially constructed nature of firms and markets implies that they are meaningful entities whose nature and operations vary according to differences in meaning systems and dominant rationalities. Thus, rules of the game, business recipes, and economic rationalities may vary considerably between countries (Ibid., pp. 122, 125). No set of rules can ever be self-contained and complete. Every act of human understanding is essentially based on unarticulated background of what is taken for granted. It is when we lack a common background that misunderstandings arise, in which case we are forced to articulate the background, and explain it to ourselves and to others (Tsoukas, 1996, p. 16). A recipe, e.g., an industry recipe (Spender, 1989), consists of a set of 
background distinctions tied to a particular field of experience. It is learned within the context of discursive practices (Tsoukas, 1996, pp. 20-21).

The world of social systems is brought forth in language. Particular usage of words tends to be specific to national cultures, to regional sub-groups within a nation, as well as to organisations and is embedded in specific contexts of meaning. The same applies to professions. For instance, everybody participating in a medical operation knows the meaning when the surgeon shouts "Scalpel!". Therefore, the interpretation even of individual words is based on highly contextual knowledge and might vary between different contexts. Socialised organisational knowledge allows for less to be said than what is known (Ibid., p. 119).

In international management, a basic precondition is to develop differentiated discursive practices that allow for global discourse across all units. Specialised discourse practices at a geographical level (e.g., local subsidiaries and networks) and at a professional level (communities of practice) should complement the system-wide discourse. Globally operating firms have to provide for nested consensual domains and common evolutionary motors across the dispersed units including a framework that allows for a co-evolution of subsidiaries and local environments. Meaning provides stability in the form of organisational memory, structures, and routines but is also subject to a continuous process of new meaning generation. The variety of the internal and external context of globally operating firms provides a high self-complexity and rich source for the generation of new meaning. In management literature this is a central aspect in innovation and knowledge-based approaches.

Evolutionary mechanism of social systems. In terms of Waddington (1976, p. 11), “man's development of language as a means of communicating information and instructions... provided him with an enormously powerful mechanism of evolution". Social evolution is much faster than biological evolution as it is based on the processing of meaning. Even in the global context, the unit acts of this process increasingly proceed on a zero-time basis due to information and communication technologies. The basic evolutionary mechanism of social systems is the operation of meaning on the basis of guiding differences. Guiding differences are distinctions that steer the possibilities of processing information. For example, these guiding differences can acquire the property of a dominating paradigm if they organise a supertheory in such a way that in practice all information processing proceeds according to them. For example, Darwin channelled the supertheory evolution into the difference between variation and selection (Luhmann, 1995, p. 4).

While most economic and management theories are instrumental and focused on normative issues in order to provide managers with means to pursue their goals, evolutionary theories explain mechanisms of change. They are open-ended and not directed towards the achievement of defined goals. The latter only applies to the teleological mechanism. The processing of meaning on the basis of distinctions, i.e., opposites, drives social evolution. In formal (static) logic, contradiction has the connotation of falsity. That is, a contradiction proposes that something is both the case and not the case at the same time and is, therefore, logically impossible because "tertium non datur" (Hatch, 1997, p. 321). From a temporal perspective, however, the dialectic tension between two opposites provides the evolutionary motor that instills social systems with dynamics. Guiding differences are central sources of variation and selective retention as they provide the basis for the recursive interaction between meaning processing and action. For example, business organisations may be driven by the temporal needs for more expansion (e.g., diversification), then (as a consequence) for more consolidation and selective focusing (e.g., concentration on core competencies). Firms hence are floating between the extreme points of guiding 
differences, which are constitutive for their evolution. In the global context, a critical task of firms thus is to define and to actualise the guiding differences that are most important for their economic and reproductive success. These guiding differences provide the basis for perception, interpretation, and decision-making. They direct the attention and preferences of decision-makers and are decisive for the pattern of self-organisation.

The processing of meaning, actions, and decisions by guiding differences constitutes the autopoietic evolutionary motor of social systems. Globally operating firms have to develop the requisite self-complexity and resonance capacity to facilitate the autopoietic reproduction across dispersed units in a globally differentiated and nested hierarchy of social systems.

Globally operating firms are subject to internal and external pressures for local adaptation and global integration. This paradox must not be neglected but appear as a dominating guiding difference, which has to be balanced dynamically. The more a firm understands and manages the dominant paradoxes underlying its business, the higher is its self-complexity and evolutionary capability.

Complexity of social systems. A major task in globalisation processes is the creation and reproduction of organised complexity across the globally differentiated units produced by internationalisation activities. In effect, complexity means being forced to select; being forced to select means contingency; and contingency means risk. Each complex state of affairs is based on a selection of relations among its elements, which uses to constitute and maintain itself. The focus in business organisations with globally dispersed units therefore is on the relational structure among these units, or in other terms, the internal network of relations among the units and the external network of relations with the organised environment.

Clearly, systems lack the requisite variety that would enable them to react to every state of the environment, that is to say, to establish an environment exactly suited to the system. There is no point-for-point correspondence between system and environment (such a condition would even abolish the difference between system and environment). The system's inferiority in complexity must be counter-balanced by strategies of selection (Luhmann, 1995, p. 25). Particularly, the differentiated global context provides an immense complexity. Firms have to develop the capacity for the dynamic selection and design of their networks of relations or, in terms of systems theory, their "Eigenkomplexität” (self-complexity).

Resulting from the historical accumulation of system states like knowledge and experience, self-complexity is the capability of a system not only to reduce the unlimited environmental complexity, but also to transform it into a specific order by using rules, which depend on the conditions of reproduction and co-ordination provided by the existing self-complexity (Willke, 1994a, p. 103). The accompanying "Resonanzfähigkeit" (resonance capacity) is the capability of a social system to equilibrate, respond, and absorb external perturbations and to act with regard to them. In the knowledge-based view of strategic management, a similar concept was developed and termed absorptive capacity (Cohen \& Levinthal, 1990).

Social systems are characterised by the principles of recursiveness and self-similarity. A social system and its subsystems are self-similar and linked in a recursive interplay (Malik, 1984, p. 104). All subsystems are wholes with boundaries and all characteristics of a social system linked by self-similar principles of organisation. In this layered structure, allopoietic organisation has to define arenas for self-organisation in the form of context management, which proved to be particularly valuable in international management (Bartlett \& Ghoshal, 1987). The explanatory value of self-organisation and autonomy is particularly high in international business because of 
the differences in environmental conditions. Self-similarity reduces structural complexity, and makes transparency, communication, and substitutability of elements easier. Self-similar and recursive structures may also facilitate information processing (e.g., data structures, algorithms) and knowledge management (e.g., knowledge integration and distribution). Self-similar structures may be designed on the basis of subsidiaries or other types of organisational units (Schiemenz, 1994, p. 304).

In firms, no matter where or how small, when the level of observation is changed (e.g., when studying learning processes at individual, group, business unit level), new processes are revealed, each resembling the overall process. They are always similar but never identical (von Krogh \& Roos, 1995, p. 82). For example, MNEs pursuing a multinational strategy are characterised by a duplication of activities across countries and local autonomy. Subsidiaries are given equal treatment and develop similar activities along the whole value chain. Despite local differences, these subsidiaries will exhibit a great similarity. Decision-making in organisations, including rational choice models, bureaucratic models and political models of decision-making, can also be said to be self-similar as it can applied to all organisational levels (Ibid., p. 82). How an individual autopoietically produces new knowledge (new distinctions) is similar to the way a business unit produces knowledge, which in turn, is similar to the way an organisation produces knowledge. This may even be extended to inter-organisational or societal levels. At various levels of observations, the individual, group, or organisation are autonomous, simultaneously open and closed, self-referential, and observing systems. In general, globalisation leads to an increase in the complexity of decision-making (Schiemenz, 1994, p. 286). The design of self-similar structures is a main instrument to reduce global complexity.

Interpenetration of system and environment. A particularly neglected research area in strategic and international management is the dynamic coupling of organisational actors and the interaction between individual level understanding and organisational action (Lyles \& Schwenk, 1997, p. 52). From a knowledge-based perspective, complex organisations are conceived as repositories of knowledge and exist as communities in which varieties of functional expertise can be communicated and combined by a common language and organising principles. A firm's functional expertise is nested within a higher-order set of recipes that act as organising principles. A firm's knowledge may also consist of the information of other actors in a network, as well as the procedures by which resources are gained and transactions and co-operation are conducted (Kogut \& Zander, 1992, p. 384). Such a view is pragmatically appealing but lacks theoretical foundation, as the ontological status of a firm remains unclear. A repository cannot reproduce itself. It may only be subject to transformation on the basis of rational choice from outside. Thus, viewing firms as repositories of knowledge, who will decide as no individuals or organisational actors are included as elements?

In the social systems view, however, interpenetration provides the basis for structural coupling, consensual domains, and the co-evolution of psychic and social systems. Interpenetration is an intersystem relation between systems that are environment for each other. While penetration exists when a system makes its own complexity available for constructing another system, interpenetration exists when this occurs reciprocally, that is, when both systems enable each other by introducing their own complexity into each other (Luhmann, 1995, p. 213).

Interpenetration may emerge: (1) externally between distinct systems (e.g., organisations); (2) internally between distinct parts of a system (e.g., organisational units); and (3) between systems of different ontological levels (psychic and social systems). Psychic systems (individual actors) constitute social systems on the basis of 
meaning. The interpenetration of psychic and social systems is based on meaning. Psychic systems supply social systems with adequate disorder and vice versa. The construction of social systems follows the principle of order from noise. Social systems come into being on the basis of the noise that psychic systems create in their attempts to communicate (Luhmann, 1995, p. 214). Actions are simultaneously the actions of human beings and the possible building blocks of social systems (Ibid., p. 215). From this perspective, human beings constitute the environment of social systems. Psychic systems—or cognitive systems (in terms of Maturana)—are subsystems of human beings and belong to the environment of social systems (Ibid., p. 255). Psychic systems are autopoietic systems based on consciousness (Ibid., p. 262). Psychic systems and social systems come into being in the course of co-evolution (Ibid., p. 271). The relationship of human beings to social system is one of interpenetration (Ibid., p. 240). Only those stocks of meaning in the consciousness of individuals that belong to a social system are parts of it. The same applies to communications and actions by the individuals on behalf of the system.

The relation between individuals and social systems. From the autopoietic perspective and akin to management approaches, individuals (e.g., employees) are not elements of the organisation, but may be regarded as resources, providing labour to conduct necessary activities, and to process meaning in terms of innovation, planning, decision-making, and control. Individuals act as stakeholders, catalysts, and means for the foundation and maintenance of autopoietic social systems. They contribute to the reproduction of autopoietic social systems but are not part of them. This enables individuals to participate in the reproduction of various different social systems without becoming extinct when any one system dies. Only what an individual invests in terms of acting (working) and meaning processing (planning, thinking, ideas, desires, expectations, etc.) on behalf of the system becomes part of it. All other aspects of an individual's life remain outside of the system but will certainly be recursively influenced by it. On the other hand, individuals do not only receive direct incentives from the social system but also valuable meaning and access to relations. As argued in the case of born globals, founders invest the meaning (knowledge, experiences, intuition) and the relationships generated in their professional history as founding capital in the new venture. As DiMaggio and Powell (1983) contend, the building blocks for the formation of social systems have become virtually littered in the social space. Founders of born globals appear to have collected enough such building blocks on a global scale to set-up new ventures viable in this context.

Individuals also take boundary-spanning roles, facilitating the interpenetration of social systems their structural coupling, and the development of consensual domains between them. They provide the autopoietic system with the capability to import information and other necessary resources, and to export its products in exchange. From the institutionalisation perspective, individuals act as isomorphic ventilators, instilling the social system with meaning from the social environment and communicating meaning generated by the system to their social environment. Individuals are the generators and transmission belts for the recursive interplay of meaning and action. The autopoietic system thus depends on the organisation of this recursive interplay but not on the concrete structure at any given point in time (Maturana, 1985).

As the firm or other organisation provides the means to achieve the goals of social actors, it attracts them to participate. Due to double contingency and interdependencies with exchange partners, the probability of structural coupling with other social actors rises as more individuals put their stakes and resources into the organisation. Individual motivations of stakeholders and double contingency with other social actors constitute the inherent tendency for growth, which is typical for living systems. In the global context, individuals in terms of 
psychic systems are socialised quite differently and intercultural differences may demand more efforts in the development of shared meaning and activity structures. Both more conscious efforts and learning-by-doing may become necessary to bridge cultural and contextual differences by developing globally nested consensual domains between and across dispersed organisational units.

Recursive interplay of action and meaning structure. A social system is constituted as an action system, but must presuppose the communicative context of action. Both action and communication are necessary, and must constantly co-operate in order to enable reproduction out of the elements of reproduction. Reproduction means only production out of what has been produced; for autopoietic systems this means that the system does not end through its actual activity, but goes on. This going on depends on the fact that actions (whether intentionally or not) have communicative value. Communication and action are recursively related (Luhmann, 1995). The autopoietic organisation of a social system is constituted by the recursive interplay between meaning and action level.

The evolution of a social system is driven by the recursive interplay of its activity structure and its meaning structure. Actions and communications are the unit acts in this process.

Communication or processing of meaning in general recursively drive the reproduction of the underlying meaning structure, which is first imprinted by the founders and then begins its autopoietic reproduction. The same applies to the action level, where actions recursively drive the autopoietic reproduction of the activity structure. The elements of an autopoietic social system hence are meaning and social acts—not individuals. The autopoietic system is dependent on the interpenetration and structural coupling with individuals who provide their contribution in form of necessary resources-including the capacity of meaning processing and activity conduct - and who in turn receive the expected incentives by the autopoietic system. As long as the social system finds individuals (stakeholders) who participate in this interplay, the autopoietic system will survive. The system may even change its purpose, its technology, or products as long as it maintains its reproduction, i.e., its autopoietic organisation.

\section{Change and Reproduction of Global Social Systems}

The structure of elements and relations in social systems is basically stable over a certain period of time. A given organisational structure restricts the amount of possible choices and relations among elements and behaviours and consists of a structure of expectations regulating legitimated behaviour (Luhmann, 1995, p. 283). Expectations are the autopoietic requirement for the reproduction of actions. There are no other structural possibilities for social systems because social systems temporalise their elements as action-events. Expectations translate meaning into intended action and its implementation. Decisions legitimate expectations and make them explicit. An action therefore is always oriented by expectations. Routinisation and institutionalisation can reduce the need for decision-making as expected actions are stabilised. Routine and institutionalised actions thus lose the character of a decision (Ibid., pp. 293-295). They reflect organised complexity and reduce the amount necessary decisions but may also become rigid and dysfunctional.

In globally differentiated systems, the complexity and dynamics would call for routines and institutionalised action in order to reduce the complexity of decision-making. However, as local contexts and expectations may differ profoundly, such standardisation may be difficult to achieve. One basic solution is the minimisation of 
interdependencies by decentralisation, another is the development of consensual domains between and across globally differentiated units. The latter allows for a commensurability of expectations across the units, providing a joint orientation towards intended actions and transformations. As a minimum condition, the units have to develop equifinal meaning (e.g., expectations) by communication, which allows for directed organised action—even though there are diverging interests, motives, and interpretations. A basic condition in globally operating firms is the development of interculturally suitable communication and meaning structures, which may provide the necessary transparency and direction. Internationalisation processes involve both increases and decreases in the geographic and cultural extension of a firm. Management in complex global systems therefore includes the increase in the global requisite variety, in the capability of organisational resonance in globally differentiated environments, and the respective processing of contingencies in terms of the behavioural potential of the system (Müller, 1996, p. 73).

Differentiation and integration. Historically, the first move on the way from a mechanistic general systems theory to an evolutionary theory of social systems and finally to an evolutionary theory of globalisation is the replacement of the traditional difference between whole and part by that between system and environment. This transformation (von Bertalanffy, 1950) enables to interrelate the theory of the organism, thermodynamics, and evolutionary theory, constituting the theory of system differentiation (Luhmann, 1995, p. 6). In economic terms, differentiation and subsequent integration of social relations in the differentiated systems constitutes both horizontal and vertical functional specialisation. The evolutionary process of differentiation and integration therefore creates both variation (innovation) and more efficiency in the functional systems. Differentiation and integration, i.e., the evolutionary motor of social systems, is constituted by the continuous, recursive interaction between their two constituting levels of meaning and action. In the course of its evolution, the interpretation of perceptions of a system determines its activities. The activities of a system, in turn, determine the interpretations of its perceptions. Such a circular explanation is necessary and valid because it infuses a system with its dynamic (von Foerster, 1985, p. 47).

After the founding process of a new social system, the process of differentiation and integration sets in internally and with regard to the coupling with the environment. Internally, the social system differentiates new subsystems (e.g., organisational units), which are themselves social systems due to the principle of self-similarity. The social system unfolds an internal nested hierarchy of social systems. The self-similarity of these (sub-)systems allows for consistent communication, action, and organising principles. In the process of globalisation, the social system encounters perturbations, as individuals belonging to other national or cultural systems—-living and socialised in a different cultural context—constitute new differentiated subsystems.

Globalisation is characterised by the expansion of social systems and the development of network relations on global scale. Globalisation thus provides a fertile context for the increasing formation, expansion, and linking of social systems in a recursive, self-fuelling process. The principle of differentiation and integration leads to complementary processes of globalisation on organisation level, here exemplified by the difference of global vs. local:

(1) It may be argued that global systems like MNEs differentiate subsystems (e.g., subsidiaries), which adapt to local conditions and act as bridges to build consensual domains and structural couplings with systems in the local environment. The MNE thus may gain access to local resources and options to export the systems' 
products. The MNE differentiates own subunits but also develops external interdependencies in global scale, further increasing the probability of system formation and differentiation. In order to maintain their steady state and autopoietic reproduction, MNEs commit substantial resources to the integration of their subsystems. With increasing internal differentiation and external interdependencies, the complexity of relations increases. Besides the mere quantity of relations, it is the variety of environments and the resulting differentiation of internal subsystems, external interdependencies and consensual domains, which produces the immense complexity of MNEs. These have to develop the requisite variety in form of organised complexity in order to maintain their identity and their autopoiesis. This induces the import and integration of organised complexity in the form of meaning. MNEs need to preside over a variety of knowledge of the diverse social spaces in which they act and must develop the capacity to integrate this knowledge in the internal process of meaning generation and reproduction. The generation and diffusion of knowledge at both system level (global) and subsystem level (e.g., local) becomes a critical capability of MNEs in order to maintain the evolutionary interplay between meaning and action levels across all subsystems.

(2) Contrary to MNEs, many local organisations, such as SMEs, do not preside over globally dispersed resources and interdependencies. Such local firms have not reached the global level by internal differentiation and integration and thus these two subprocesses of social evolution still await geographic extension. Local firms may follow the course of internationalisation by internal differentiation, i.e., FDI, or by the establishment of interdependencies with other, globally dispersed organisations. In the first case, integration is primarily focused on internal relations. In the second case, the harmonisation of globally differentiated consensual domains becomes a main task in order to maintain a symbiotic co-evolution with the now geographically and culturally differentiated environment. Though circular in a recursive perspective, differentiation precedes and even induces integration in a sequential perspective. Internationalisation efforts of SMEs therefore often concentrate on the entrepreneurial side, i.e., differentiation, and neglect the integrative aspect of globalisation.

(3) Complementary to the single firm or intraorganisational globalisation perspective, which distinguishes global firms (MNEs) and local firms (majority of SMEs), the local vs. global difference may also be applied to interorganisational networks. There are strong competitive advantages of both local and global networks. Local networks provide advantages of flexible specialisation, innovative milieus, cultural homogeneity, and social capital from local embeddedness. As in the case of MNEs, global interorganisational networks provide substantial advantages from global variety, global co-specialisation, and co-ordination. Contrary to MNEs, they have more flexibility and possibilities of niche specialisation. While global interorganisational networks certainly provide access to a higher variety and offer a higher capacity to exploit location advantages and to leverage competitive advantages, their integration is very difficult and may impede more complex forms of activities. Local networks, on the other hand, are much easier to coordinate due to their local embeddedness but do not provide the global diversity of their global counterparts. Increasingly, local networks seem to develop relations with global networks, and vice versa. Globalisation thus induces the formation of multi-layered networks from the local to the global level.

The described global differentiation and integration of MNEs, the internationalisation of MNEs, and the emergence of multi-layered networks on a global scale induce the liquefaction of global competition, which sets the standards for the global evolution of firms in the context of economic globalisation. 
Evolutionary motors. The basic principle of evolution is not teleological, towards some however defined higher perfection. Rather, the basic principle is "to get out of the way". In biology, this means to get out of the way of competitors, predators, and other environmental threats. In societies, social systems encounter such restriction in terms of other social systems, i.e., organisations, and legitimacy. The irony with the process of globalisation is that the globalisation itself strictly limits the possibility to get out of the way. Globalisation causes a domestication of the global arena. While discoveries and geographic expansion in ancient times basically reflected a spatial extension of a social system, they now lead to changes within the increasingly dense fabric of global networks. In addition to the principle to get out of the way in order to find a stable supply with resources and to pursue the basic function and goals of the system, social systems have also been described as being designed for the pursuit of individual goals of the stakeholders. As such, they are also instruments and subject to allopoietic reproduction. There are basically four mechanisms of change in social systems identified by organisation theory (van de Ven \& Poole, 1995). In addition, the mechanism of meaning processing by guiding differences by social system may be regarded as a fifth mechanism. All the five mechanisms provide the dynamics that drive the principle of differentiation and integration in social evolution.

(1) Life cycle mechanisms

Life cycle mechanisms are the most common holistic explanation of transformation in the management literature. The typical progression of change events in a life-cycle model is a unitary sequence, which is cumulative and conjunctive. A singular discrete entity that undergoes change yet maintains its identity throughout the process exists. The entity passes through stages distinguishable in form or function. A programme, routine, rule, or code exists in nature, social institutions, or logic that determines the stages of development and governs progression through the stages. The logic of life cycle models is appealing as social systems have a birth in terms of foundation, growth, and often, even death. An important restriction is the missing consistency of what happens between birth and death. There are no consistent overarching principles or phases applying to all organisations or other social systems. On the contrary, population ecology showed that contrary to biology, the probability of death in the case of organisations decreases with increasing age. The same applies to transformation processes. A study by Singh, House and Tucker (1986, p. 606) suggests that organisational changes made earlier in the life cycles are more likely to influence the hazard of death. The life cycle has been explicitly chosen by Vernon (1966) as the motor for change in his international product life cycle model. Life cycle mechanisms are also underlying all other stage models of internationalisation, though in combination with other mechanisms.

(2) Teleological mechanisms

Teleological mechanisms drive the development of an organisational entity toward a goal or an end state. The organisational entity is purposeful and adaptive; by itself or in interaction with others, the entity constructs an envisioned end state, takes action to reach it, and monitors the progress. Such a mechanism perfectly fits in the case of organisations as rational, purposive, and goal-directed social systems. Consequently, the teleological mechanisms dominate the management perspective due to their instrumental value. The purpose of an organisation is first defined by the founders and imprinted at foundation. Later, the respective stakeholders continuously renegotiate the purpose and the specific goals dependent on their power positions. Strategic contingency theory, exchange theory, and resource dependence theory provide a great variety of arguments in 
this regard. The basic means of social teleological mechanisms are decision-making processes. Decision-making is not only necessary to make expectations explicit in order to implement the intended activities. In addition, negated possibilities may determine the system more than pursued possibilities because they cannot be corrected or adapted by learning. They influence the structural drift of the system much more than the accepted possibilities, which can be modified by further decisions. Consequently, it may be a reasonable maxim to decide in a way that decisions extend the decisional space and autonomy of the system (Luhmann, 2000, p. 199). Structures in organisations have the function of premises for decisions and hierarchies are thus priori decisions on how decisions shall be made (Luhmann, 1971, p. 69). Decision-making has received extensive attention in literature on international business with regard to strategy-making under the perspective "centralisation vs. decentralisation” (Garland \& Farmer, 1986; Ronen, 1986) and particularly in the process school of international business, which put the decision-making context—particularly between MNE headquarters and subsidiaries—at the centre of the transnational model.

(3) Dialectical mechanisms

Dialectical mechanisms develop in systems, which are subject to contradictory or colliding forces. Historically, such mechanisms have particularly been identified in contexts of political and power struggle, e.g., in historical materialism (work vs. capital). In the operation of dialectical mechanisms, initially opposing thesis and antithesis are fused by a synthesis, which becomes a stable compromise for a period of time and can become the new and challenged thesis as the dialectical process continues. Change and stability thus co-exist in dialectical synthesis. The dialectical view particularly applies to the context of globalisation and particularly to MNEs, which already internalised the basic dialectic of local adaptation vs. global integration.

(4) Evolutionary mechanisms

The evolutionary motor causes cumulative changes in social systems. Change proceeds through a continuous cycle of variation, selection, and retention. In contrast to Darwinian evolution where traits are inherited through intergenerational processes, the Lamarckian concept argues that traits are acquired within a generation through learning and imitation. A Lamarckian view thus appears to be more reasonable in the case of social evolution. In contrast to blind Darwinian evolution in biology, active selection by human agents occurs at all stages of the process of social evolution. Evolution in social systems is constituted by evolution of knowledge (Loasby, 1999; Boulding, 1981; Veblen, 1899). The variation and selective retention (VSR) mechanism is consequently the first mechanism used to explain evolutionary dynamics by the knowledge-based view. Evolutionary changes are not always intentional and media such as the Internet provide a huge output of new ideas, knowledge, and ways to do things that instill social systems in with increasing local and global dynamics.

(5) Autopoietic mechanisms

A fifth motor not included by van de Ven and Poole is the autopoietic motor of meaning processing by guiding differences in social systems. The evolutionary mechanism of social systems is the recursive reproduction of meaning and action on the basis of guiding differences (Luhmann, 1995, p. 4). Such guiding differences allow for the organisation of meaning by building dynamic relations. For example, as shown by Ghoshal (1987), the distinction of global integration vs. local adaptation may be applied to organise knowledge from the industry level, to firms, and even to individual activities. A basic task in the evolution of an organisation is to identify the most critical guiding differences for their successful reproduction. The evolution of the 
organisational meaning structure and consensual domains across units and with external partners thus may be facilitated. The guiding differences provide the basis for perception, interpretation, and decision-making. They direct the attention and preferences of decision-makers and are decisive for the pattern of self-organisation. In the process of globalisation, a system has to develop the requisite organised complexity by integration of guiding differences, which allow for a viable perception and meaning processing in the globally differentiated context. Generally, more than one motor comes into play because the organisational context of development and change extends over space and time in any specific case. There may also be some degree of nesting, timing/sequencing, and complementarity of motors.

\section{Co-evolution of Social Systems and Their Environment}

The basic condition for the co-evolution of social systems is their capability to communicate, to interact, and to understand and interpret the communication and actions of each other. When these conditions are given and interaction is taking place, this is called interpenetration. Interpenetration exists when two systems enable each other by introducing their own complexity into each other (Luhmann, 1995, p. 213). Social systems do this by means of meaningful communication and action. As argued above, individuals act as catalysts and channels for the flow of such social acts. Interpenetration provides the basis for structural coupling, consensual domains, and the co-evolution of systems. Meaning enables psychic and social system formations to interpenetrate, while protecting their autopoiesis (Ibid., p. 232). Interpenetration of social systems from different cultural environments is much more difficult than within a homogeneous context. First, the basic means of communication, language, is different. Communication may be simply impossible, but even qualified personnel may not perceive minute connotations of communications formulated in the language of the foreign partner. Second, different cultures have different preferences, norms, interpretations, habits, and even different modes of meaning reproduction. The interchange of meaning, ranging from simple information to the transfer of best practice or technology thus represents a major obstacle to international or even global interaction. Particularly more dynamic and complex forms of interchange like global innovation processes may be very difficult between culturally different systems.

The co-evolution of social systems thus presupposes a parallelisation of structural elements and acts in their reproduction. The increasing differentiation of social systems and the resulting dynamics in the globalisation process may lead to asymmetrical ageing in the co-evolution of structurally coupled organisations and even of their subunits. Structural elements and relations become temporally more differentiated. Their integration may be facilitated by intentional mutual ageing (Schütz, 1932, p. 111), which becomes a key to successful co-specialisation and co-operation across globally dispersed markets with different dynamics. As the basic structural means for the co-evolution of social systems, the construction of consensual domains can be viewed as the central demand resulting from globalisation processes (see Figures 1-2). New organisational units or co-operation partners have to be integrated into the ongoing structures and operations, so that the construction of a shared reality may be the fundament for successful interaction. Globally dispersed activities lead to an increasing necessity of consensual domain construction and integration. Local subsidiaries have to develop their consensual domains and structural couplings in their local context and thus they may be the source of innovative processes for the whole network. 


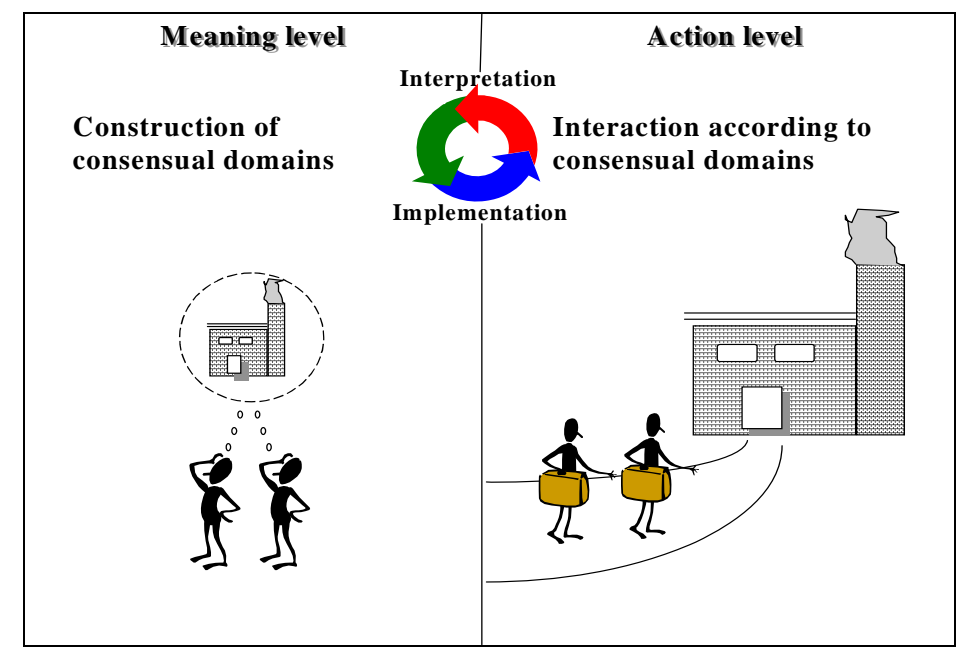

Figure 1. Construction of consensual domains.

On the other hand, standardised knowledge in form of best practices, standardised processes, and products or structural arrangements have to be conveyed to new units and partners to guarantee efficiency and continuation as well as a boundary-spanning fit with existing structures and processes. The development of transparency in the own structures and operations is therefore a very important step to develop the ability to communicate and construct new realities with partners, co-operation partners as well as other internal organisational units. Particularly the variety of consensual domains on a global scale can be viewed as the central challenge to the management of globalisation. It can be the source of conflicts and misunderstanding as well as a source of new ideas and innovations and thus exerts a fundamental impact on the evolution of a company.

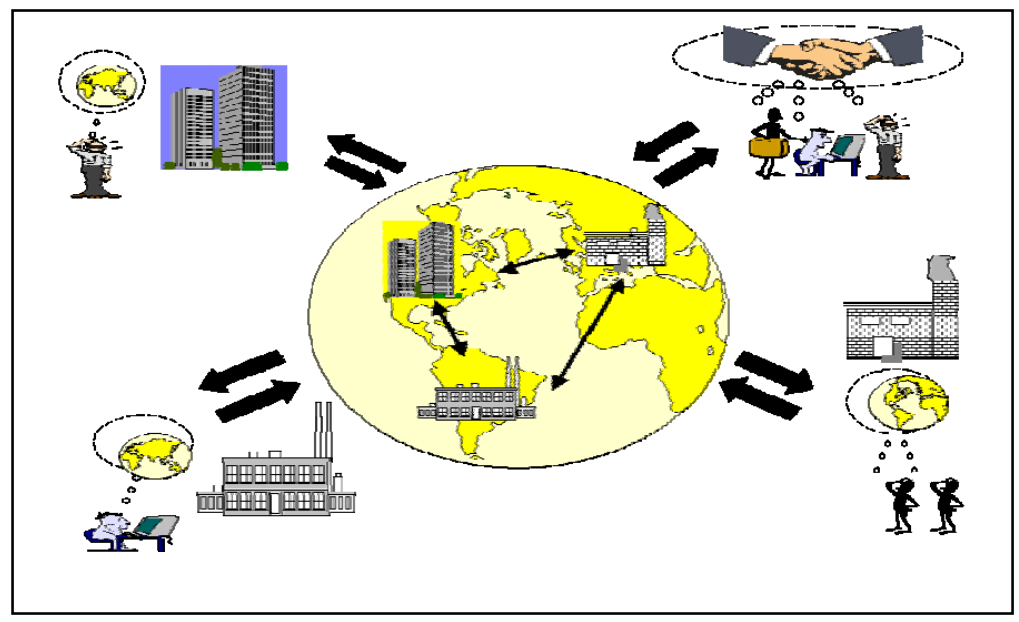

Figure 2. Integration of local and global consensual domains.

As globally differentiated subsystems are constituted primarily by local individuals, they are instilled with meaning generated in the local context. A large variety of meaning and interpretations is thus imported into the local subsidiary due to the interpenetration of social and psychic systems. Local subsidiaries are rich sources of new meaning and interpretation. At the same time, individuals from the local context have to be instilled with system- or firm-specific meaning. This includes the transfer of knowledge and organisational culture. Individuals are the linking pins between the local environment and the subsidiary and are the means of local interpenetration 
and the development of local consensual domains. In addition, they act as linking pins between the local sub-system (subsidiary) and the network of globally dispersed subsystems generating and reproducing the respective interpenetrations and consensual areas. Individuals in subsystems thus have to develop a Janus-faced role, which allows for a dynamic balancing of the two perspectives. Once again, the principle of evolution by the processing of guiding differences becomes apparent. Individuals may be trained and sensitised to focus on such central guiding differences in order to allow for a common orientation on a heterarchic rather than hierarchical basis. Such general capabilities of system members provide the fundament for the more specific globalisation capabilities.

\section{Methodological Consequences}

The conceptualisation of the globalisation of firms in terms of social systems at a first glance introduces a pretty clumsy group of concepts (and in particular wordings) but on the other hand it provides the only really authentic way to define globalisation as an evolutionary process (of social systems). It provides an explanation of the globalisation of social systems from a minimum level such as small firms to the evolution of global society as a whole. Of course, this has implications for empirical research.

The ontological position determines assumptions about the nature of social science (Karami, Rowley, \& Analoui, 2006, p. 46). Assumptions of an ontological nature concern the very essence of the phenomena under investigation. It reflects the position if reality is of an objective nature or the product of individual cognition. Objectivity is often discussed as one side of a polarity as opposed to subjectivity on the other side. Conceptualising firms as social systems implies both observing objective attributes (particularly in terms of a first level system) and subjective attributes (e.g., second level interpretations of meaning or actions by managers or even other social actors (re)producing social meaning and action on behalf of the firm).

Assumptions of an epistemological nature express how one might begin to understand the world and communicate this as knowledge to others. There are two extreme positions whether knowledge is something objective, which can be acquired (positivism), or is something which has to be personally experienced (interpretivism). Social systems theory allows for an integration of both.

Conceptualising firms as social systems provides a more balanced perspective as it aims to be more holistic and is beyond the extremes of interpretivism and positivism with their respective blind spots. These seemingly competing scientific perspectives can be integrated by the fact that perception needs dualities in order to work - even in scientific research. Nonetheless, only both sides of a duality combined form a "whole" reality. By conceptualising firms as social systems this dual character might be captured. As a starting point serves the dual character of social systems. The traditional view of firms in terms of organisations is based on the assumptions that they are constituted by individuals as their elements who are decision-makers and social actors. This allopoietic perspective provides a teleological, goal-directed approach to the management and development of social systems but does not allow for an evolutionary view. Allopoiesis is defined as a production of something else than itself. In management theory, it resembles the traditional perspective of purposive, rational planning and implementation, including the construction of formal hierarchical organisation, in which lower levels are designed and controlled. Informal and emergent properties from this view are excluded or invisible. Allopoietic systems are undoubtedly the precursors of autopoiesis in social systems-allopoiesis is the framework, a 
condition, within which autopoiesis can take place (Zeleny, 1981, pp. 95-96). The view of organisations as allopoietic social systems is the traditional view of purposeful, instrumental, and goal-directed systems constituted by individuals. It has traditionally been dominating organisation and management theory. For example, many empirical studies focused on formal roles and organisational units (e.g., subsidiaries, divisions). The function of the organisation is to attain the formulated purpose and specific goals by means of specialisation and co-ordination of organisational processes, roles, and units. From the allopoietic perspective, teleological processes of planning and decision-making drive evolution. The firm as an allopoietic system basically reflects an objective reality and can be analysed with quantitative methods. Formal aspects such as number of employees, their qualification, the allocation of resources and formal organisational or strategic properties can be measured quantitatively. The allopoietic conceptualisation of social systems creates a conflicting view of social systems as being real either objectively (positivism) or (inter-)subjectively (interpretivism), creating an "either/or" conflict in research.

With increasing dynamics, formal and objective phenomena begin to lose their value as an accurate and stable directory of where knowledge and capability reside and how they can be accessed. An instrumental, teleological approach does not allow for an authentic application of evolutionary principles because this would require that social systems are capable to reproduce themselves on the basis of their elements (Maturana, 1985). Autopoietic systems are capable to reproduce themselves. In this view, firms are not only instruments to achieve the goals of the stakeholders but they take a life on their own (Selznick, 1947).

In contrast to an allopoietic approach, which still assumes individuals to be the elements of social systems, the adaptation of the concept of autopoiesis (self-reproduction) to social evolution appears to be conceptually possible by an adaptation of the mechanism of the reproduction of components. Social acts such as communication or action may be components of self-referential, but not of autopoietic systems: they do not exist independently from the existence of acting individuals and communicative acts do not produce new communicative acts themselves but trigger them in individuals.

Thus, a social system may only be regarded as being autopoietic by an ontological change of the system level. This implies: (1) a complete conceptual exclusion of individuals from the concept of social system; and (2) a conceptualisation of social acts (communications, actions) as the only components of the social system. It is thus possible to develop an ontology of social systems, in which the states (social acts) adopted by the components (individuals) of an allopoietic system become the components of an ontologically higher system, which may be regarded as a social system of a second level or order (Roth, 1986, p. 212). As enacted, second-level social systems, they are both subject to voluntary, intentional change and emergent, evolutionary change. Contrary to autopoietic systems, in allopoietic systems, the organisation itself does not produce the elements and processes constituting it as a unity (Maturana, 1985, p. 177).

Autopoiesis and allopoiesis are complementary rather than exclusive characterisations for a system (Varela, 1981, p. 39). Social systems can be conceptualised both as first-level, allopoietic systems constituted by social actors and as second-level, autopoietic systems, constituted by social acts as their elements. The individuals constituting a social system by their social acts do not enter the autopoietic system as elements. Rather, they may be conceived as stakeholders, catalysts, and primary resources, which provide all necessary tangible and intangible resources by communication and action. Hence, the elements of the autopoietic social system are all 
communications and actions on its behalf and from its perspective-not the constituting individuals. Such an ontological change also has a profound effect on the boundaries of a firm. While traditionally the focus has been on individuals (e.g., managers), geographic or organisational units, the boundaries are now defined by the (self-reproducing) network of communications and actions, which constitute the firm. Hence, a boy playing football with 10 others in India who is wearing a "Coke" shirt might be doing more for the firm than a manager sitting at HQ in Atlanta thinking about his next holidays. The former is communicating the firm's image to others while the latter is physically at work but processing neither communication nor action for the firm at that given moment.

The consequences are far reaching. With the new possibilities provided by media such as the Internet, triggering and directing communications and actions are becoming more important than just focusing on internal operations or organisational units. For example, blogs are used to generate awareness, communication, and directing both attention and opinion (e.g., blogs of employees or trainees). Wikis provide a forum for communications around issues that might be linked to the firm or to issues around it. Global media such as Facebook or Twitter provide a framework in which any kind of communication can form around issues and thus also potentially around firm-relevant issues. Firms therefore increasingly have to generate beneficial communication and to perceive influential areas where communication about the firm or important factors is generated. Both communication and action are increasingly linked externally, for example through events (also communicated via media) that are organised in order to trigger feedback and to attach the firm's image to certain issues.

Members of a social system thus constitute a primary, allopoietic social system, which serves as the basis for the formation of a secondary, autopoietic social system. The latter is constituted by social acts, which may consequently also be provided by individuals that are no formal members of the primary system. As individuals are not exclusive elements of one social system, they can contribute to the autopoietic reproduction of various secondary social systems by providing them with actions and communications belonging to their path-dependent reproduction. Such a definition goes beyond the concept of social praxeology that postmodernists like Pierre Bourdieu or Jeff Everett describe as a synthesis of an objectivity of the first order (or a social physics) with an objectivity of the second order (or a social phenomenology) (Gummesson, 2006, p, 171). On balance, social systems are both autopoietic in their underlying meaning-based reproduction and allopoietic, as they depend on the intentions of the individual stakeholders. Social systems emerge on the basis of consensual domains formed and implemented by the founding individuals. They grow as other individuals or social actors increasingly contribute to their reproduction both internally as members (such as employees), or externally as exchange partners. New forms of communication such as internet communities or blogs get a totally new weight from such a perspective and allow for new forms of empirical research. Consequently, the globalisation of firms can be conceptualised as a process of global differentiation (internationalisation) and integration (global networking), driven by underlying evolutionary motors such as intentional global decision-making, globally differentiated life cycles, dialectical forces, incremental changes, and firm-specific global cycles of meaning and action generation.

\section{Conclusions}

The adaptation of social systems theory to the globalisation process of firms allows for a different 
perspective on this phenomenon. The conceptualisation of firms as social systems based on communications and actions could lead to new approaches of studying the globalisation process of firms. It also provides a framework to fit in contributions from different theoretical perspectives. Boundaries of the firm have to be redrawn. Central for the study of globalisation then becomes the extension and intensity of global communication and action on behalf of the firm rather than the focus on individuals, organisational units, or assets. The definitions and wordings are definitely very theoretical and quite clumsy but the potential contribution of evolutionary systems theory is potentially huge, as it authentically integrates the whole spectrum from biological (physical) to meaning-based (social) evolution. This also has repercussions regarding the ontology of organisations and their globalisation. For example, this also allows for a complementary rather than competitive relation of "objective" and "subjective" approaches to research of globalisation.

\section{References}

Bartlett, C., \& Ghoshal, S. (1987). Managing across borders: New strategic requirements. Sloan Management Review, 28(4), 7-17. Boulding, K. E. (1981). Evolutionary economics. Beverly Hills, C.A.: Sage Publications.

Campbell, D. T. (1960). Blind variation and selective retention in creative thought as in other knowledge processes. Psychological Review, 67(6), 380-400.

Cohen, W. M. , \& Levinthal, D. (1990). Absorptive capacity: A new perspective on learning and innovation. Administrative Science Quarterly, 35(2), 128-152.

Dachler, H. P., \& Hosking, D. M. (1995). The primacy of relations in socially constructing organisational realities. In H. P. Dachler, D. M. Hosking, \& K. J. Gergen. (Eds.), Management and organisation: Relational alternatives to individualism (pp. 1-28). Aldershot, UK: Avebury.

DiMaggio, P. J., \& Powell, W. W. (1983). The iron cage revisited: Institutional isomorphism and collective rationality in organisational fields. American Sociological Review, 48(2), 147-160.

Donnellon, A., Gray, B., \& Bougnon, M. G. (1986). Communication, meaning, and organized action. Administrative Science Quarterly, 31(1), 43-55.

Duncan, R. B. (1972). Characteristics of organisations. Administrative Science Quarterly, 313-327

Egelhoff, W. G. (1993). Information processing theory and the multinational corporation. In S. Ghoshal, \& D. E. Westney (Eds.), Organisational theory and the multinational corporation. Houndsmill, London: Macmillan, 182-211.

Fischer, H. R. (1991). Information, Kommunikation und Sprache. In H. R. Fischer (Ed.), Autopoiesis (pp. 67-98). Heidelberg: Carl-Auer-Systeme Verlag.

Garland, J., \& Farmer, R. (1986). International dimensions of business policy and strategy. Boston: Kent Publishing.

Ghoshal, S. (1987). Global strategy: An organizing framework. Strategic Management Journal, 8(5), 425-440.

Giddens, A. (1984). The constitution of society. Cambridge, MA: Polity Press.

Hatch, M. J. (1997). Organisation theory: Modern, symbolic, and postmodern perspectives. Oxford: Oxford University Press.

Hejl, P. M. (1984). Towards a theory of social systems: Self-organisation and self-maintenance, self-reference and syn-reference. In H. Ulrich, \& G. J. B. Probst (Eds.), Self-organisation and management of social systems: Insights, promises, doubts, and questions (pp. 60-78). Berlin: Springer-Verlag.

Jantsch, E. (1986). Die Selbstorganisation des Universums: Vom Urknall zum menschlichen Geist. München: Deutscher Taschenbuch-Verlag.

Johanson, J., \& Vahlne, J. E. (1977). The internationalisation process of the firm: A model of knowledge development and increasing foreign market commitments. Journal of International Business Studies, 8(1), 23-32.

Karami, A., Rowley, J., \& Analoui, F. (2006). Research and knowledge building in management studies: An analysis of methodological preferences. International Journal of Management, 23(1), 43-52.

Katz, D., \& Kahn, R. (1978). The social psychology of organisations (2nd ed.). New York: John Wiley \& Sons.

Kieser, A. (1989). Entstehung und Wandel von Organisationen. In L. Bauer, \& H. Matis (Eds.), Evolution-Organisation-Management. Zur Entwicklung und Selbststeuerung komplexer Systeme (pp. 161-194). Berlin: Duncker \& Humblot. 
Kogut, B., \& Zander, U. (1992). Knowledge of the firm, combinative capabilities, and the replication of technology. Organisation Science, 3(3), 383-397.

Loasby, B. J. (1999). Knowledge, institutions and evolution in economics. London: Routledge.

Luhmann, N. (1971). Politische Planung, Aufsätze zur Soziologie von Politik und Verwaltung. Opladen: Westdeutscher Verlag.

Luhmann, N. (1975). Weltzeit und Systemgeschichte. In Soziologische Aufklärung Band 2 (pp. 103-133). Opladen: Westdeutscher Verlag.

Luhmann, N. (1988). Die Wirtschaft der Gesellschaft. Frankfurt a. M.: Suhrkamp Verlag.

Luhmann, N. (1995). Social systems. Stanford, C.A.: Stanford University Press.

Luhmann, N. (2000). Organisation und Entscheidung. Opladen, Wiesbaden: Westdeutscher Verlag.

Luostarinen, R. (1980). Internationalisation of the firm. Helsinki: Acta Academicae Oeconomicae Helsingiensis.

Lyles, M., \& Schwenk, C. R. (1997). Top management, strategy and organisational knowledge structures (L. Prusak (Ed.)), Newton, M.A.: Butterworth- Heimann.

Malik, F. (1984). Strategie des Managements komplexer Systeme. Bern: Verlag Paul Haupt.

Malik, F. (1993). Systemisches Management, Evolution, Selbstorganisation: Grundprobleme, Funktionsmechanismen und Lösungsansätze für komplexe Systeme. Bern: Verlag Paul Haupt.

Maruyama, M. (1963). The second cybernetics: Deviation-amplifying mutual causal processes. General Systems, 8, $233-241$.

Maruyama, M. (1976). Toward cultural symbiosis. In E. Jantsch, \& C. H. Waddington (Eds.), Evolution and consciousness (pp. 198-213). Reading, M.A.: Addison-Wesley.

Maturana, H. R. (1975). The organisation of the living: A theory of the living organisation. International Journal of Man-Machine Studies, 7, 313-332.

Maturana, H. R. (1985). Erkennen: Die Organisation und Verkörperung von Wirklichkeit (2nd ed.). Braunschweig: Friedrich Vieweg \& Sohn

Müller, U. (1996). Systemtheorie-Ein interdiszipinärer Ansatz zum Verständnis von Globalisierung? In U. Steger (Ed.), Globalisierung der Wirtschaft (pp. 56-82). Berlin: Springer-Verlag.

Ronen, S. (1986). Comparative and multinational management. New York: John Wiley \& Sons.

Roth, G. (1980). Cognition as a self-organising system In F. Benseler (Ed.), Autopoiesis, communication, and society: The theory of autopoietic systems in the social sciences (pp. 45-52). Frankfurt A.M., New York: Campus-Verlag.

Roth, G. (1986). Selbstorganisation und Selbstreferentialität als Prinzipien der Organisation von Lebewesen. Dialektik, 12, $195-213$.

Schiemenz, B. (1994). Hierachie und Rekursion im nationalen und internationalem Management von Produktion und Information. In B. Schiemenz, \& H. J. Wurl (Eds.), Internationales Management (pp. 285-306). Wiesbaden: Gabler.

Schmidt, G. (1986). Einverständnishandeln - ein Konzept zur 'handlungsnahen’ Untersuchung betrieblicher Entscheidungsprozesse. In R. Seltz, U. Mill, \& E. Hildebrandt (Eds.), Organisation als Sozialsystem. Berlin: Springer-Verlag.

Schulz, D. E. (1993). Ordnung und Chaos in der Wirtschaft: Zur strategischen Lenkbarkeit von Organisationen aus systemtheoretischer Sicht. München: VVF.

Schütz, A. (1932). Der sinnhafte Aufbau der sozialen Welt: Eine Einleitung in die verstehende Soziologie. Wien: Passagen.

Selznick, P. (1947). Foundations of the theory of the organisation. American Sociological Review, 25-35.

Singh, J. V., House, R. J., \& Tucker, D. J. (1986). Organisational change and organisational mortality. Administrative Science Quarterly, 31(4), 587-611.

Spencer Brown, G. (1972). Laws of form. New York: Julian Press.

Tichy, N. M. (1981). Networks in organisations. In P. Nystrom, \& W. Starbuck (Eds.), Handbook of organisational design (Vol. II, pp. 225-249). Oxford: Oxford University Press.

Tsoukas, H. (1996). The firm as a distributed knowledge system: A constructionist approach. Strategic Management Journal, 17(winter special issue), 11-25.

Uribe, R. B. (1981). Modeling autopoiesis. In M. Zeleny (Ed.), Autopoiesis (pp. 51-62). New York: Elsevier North Holland.

Van de Ven, A. H., \& Poole, M. S. (1995). Explaining development and change in organisations. Academy of Management Review, 20(3), 510-540.

Varela, F. J. (1981). Describing the logic of living. In M. Zeleny (Ed.), Autopoiesis (pp. 36-47). New York: Elsevier North Holland.

Veblen, T. (1899). The theory of the leisure class: An economic study of institutions. New York: Macmillan.

Vernon, R. (1966). International investment and international trade in the product cycle. Quarterly Journal of Economics, 80(2), 190-207. 
Von Bertalanffy, L. (1950). The theory of open systems in physics and biology. Science, 111, 23-29.

Von Foerster, H. (1985). Sicht und Einsicht. Braunschweig: Friedrich Vieweg \& Sohn.

Von Hayek, F. A. (1945). The use of knowledge in society. The American Economic Review, 19(4), 519-530.

Von Krogh, G., \& Roos, J. (1995). Organisational epistemology. New York: St. Martin’s Press.

Waddington, C. H. (1976). Evolution in the sub-human world. In E. Jantsch, \& C. H. Waddington (Eds.), Evolution and consciousness (pp. 11-15). Reading, M.A.: Addison-Wesley.

Whitley, R. (1992). The social construction of organisations and markets: The comparative analysis of business recipes. In M. Reed, \& M. Hughes (Eds.), Rethinking organisation (pp. 120-143). London: Sage Publications.

Willke, H. (1994a). Interventionstheorie: Grundzüge einer Theorie der Intervention in komplexe Systeme. Stuttgart/Jena: Gustav Fischer Verlag.

Willke, H. (1994b). Systemtheoretische Strategien des Erkennens: Wirklichkeit als interessierte Konstruktion. In K. Götz (Ed.), Theoretische Zumutungen: Vom Nutzen der systemischen Theorie für die Managementpraxis (pp. 97-116). Heidelberg: Carl-Auer-Systeme Verlag.

Zeleny, M. (1981). Autopoiesis: A theory of living organisational (pp. 3-307). New York: Elsevier North Holland.

Zeleny, M., \& Pierre, N. A. (1976). Simulation of self-renewing systems. In E. Jantsch, \& C. H. Waddington (Eds.), Evolution and consciousness (pp. 150-165). Reading, M.A.: Addison-Wesley.

Zu Knyphausen, D. (1988). Unternehmungen als evolutionsfähige Systeme: Überlegungen zu einem evolutionären Konzept für die Organisationstheorie. Munich: Verlag Barbara Kirsch. 